\title{
INTEGRATED LEARNING IN FIRST-YEAR ENGINEERING: PRELIMINARY FINDINGS AND IMPRESSIONS FROM A NEW ProjeCt-BASED Design COURSE
}

\author{
Colin P McDonald ${ }^{1}$,Kathryn Grandfield ${ }^{2}$, Calvin Zhu ${ }^{3}$, Christie Condron ${ }^{4}$, Roberta Dolling- \\ Boreham $^{3}$ \\ ${ }^{1}$ Department of Mechanical Engineering, ${ }^{2}$ Department of Materials Science and Engineering, \\ ${ }^{3}$ Department of Electrical and Computer Engineering, ${ }^{4}$ Department of Computing and Software, \\ Hamilton, ON
}

\section{INTRODUCTION}

The first-year engineering curriculum at McMaster University is a common curriculum that introduces students to the field of engineering through discrete courses focused in graphics design, computing, materials science, and the engineering profession. While these courses provide an important foundation for entry into second year (in addition to the required courses in math and science), course topics are isolated and there is very little cross-over in content from one course to the next. This paper will present initial findings and impressions of "Health Solutions Design Projects I", a project-based first-year course in McMaster's new Integrated Biomedical Engineering and Health Sciences (iBiomed) program. This new course, first offered in Fall 2017, integrates the aforementioned topics in first-year engineering into one course, and further reinforces these concepts through a series of design projects.

\section{COURSE STRUCTURE}

This full-year first-year course is requirement for all students enrolled in the
iBiomed program at McMaster University. The course is worth 10 academic units across 2 academic terms (out of 37 for the entire first year), with the balance of the students' workload comprising Math, Physics, Chemistry, Biology and a complementary studies elective. The course includes 3 lecture hours per week, 3 lab hours, and 2 tutorial hours. The lectures are taught on a rotating basis by the coinstructors (based on the alignment between the instructor's background and the particular lecture topic). Tutorials (referred to as Design Studio) provide dedicated time for students to work on their design projects. These Design Studio sessions are richly supported with an Instructional Assistant, Lab Section, Teaching Assistant and 2 faculty members from either the Faculty of Engineering or Faculty of Health Sciences.

\section{DELIVERABLES}

Five (5) design projects comprise over $60 \%$ of the overall assessment for the course, with additional assessments including several minor lab assignments, a midterm exam and a final exam. Overall, there are approximately 60 course assessments 
throughout the year, with no single assessment greater than $9 \%$ of the overall course weight. Each design project includes a number of milestones that students complete during their Design Studio, a number of final deliverables (including a unique mode of presentation for each project), and an end-of-project reflection. Each student keeps an active learning portfolio through the year that they use documenting all project work.

\section{CONCLUSIONS}

Overall, students have very much liked the projects, but have found them to be stressful and a significant amount of work. Students have also commented on the very fast pace with which certain topics were introduced (e.g., computing). This is further magnified by the fact that their peers in first-year engineering take different courses (described above) that they deem to be significantly lower in terms of level-of-difficulty. Despite these minor pitfalls, the inaugural offering of the course has been a success. Many of the pitfalls encountered have been expected and we have worked to resolve them within the academic year, rather than weight for the next cohort of students. 